$\$=$

\title{
Chemotherapy of Buxtonella sulcata in cattle in Sanandj, Iran
}

\author{
Seyed Sajjad Hasheminasab ${ }^{1 *}$, Meysam Sabour Darbandi ${ }^{2}$, Hadi Mohammadi Talvar ${ }^{3}$, \\ Hossein Maghsood ${ }^{1}$, Sara Khalili ${ }^{1}$ \\ ${ }^{1}$ Department of Parasitology, Faculty of Veterinary Medicine, University of Tehran, Tehran-Iran \\ 2 Department of Parasitology, Faculty of Veterinary Medicine, University of Shiraz, Shiraz-Iran \\ ${ }^{3}$ Islamic Azad University, Science and Research Campus, Kurdistan branch, Sanandaj, Iran \\ *Corresponding author E-mail: s.sajjad.hn@gmail.com
}

\begin{abstract}
Parasitic nematodes are one of the most important causes of production losses in most cattle-producing countries of the world. The aim of the present study Chemotherapy of B. sulcate in cattle in the Sanandj (Iran). The overall comparative efficacy of oxytetracycline and metronidazole was $66 \%$ and $32 \%$ respectively.
\end{abstract}

Keywords: Buxtonella Sulcata; Chemotherapy; Sanandj.

\section{Introduction}

Buxtonella sulcata is a commensal protozoan of the alimentary tract of ruminants and participates in the digestion of plant aliment(Huang et al., 2012).This parasite belongs to the Kingdom: Protozoa, Phylum: Ciliphora, Class: Kinetofragminophora, Order: Trichostromatidae, Family: Pyenotrichidae, Genus: Buxtonella(Al-Zubaidi and Al-Mayah, 2011).Buxtonella sulcata is very similar to a species that occur in pigs and humans (Balantidium coli)(Tomczuk et al., 2005). Studies revealed a strong relationship between the intensity of infection with this parasite (number of cysts per gram of feces) and diarrhea in cattle The first reported infection from cattle with B. sulcata in Iraq (AlQadissiyah) was in 2005(Tomczuk et al., 2005, Aayiz, 2005). This study describes the chemotherapy of B. sulcata in cattle in the region of the Sanandj (Iran).

\section{Material and method}

Faecal samples were collected between May 2013 and June 2014 in Sanandaj province. A total of 217 cattle were selected randomly according to the age, sex, health status, management system and seasons of the year from different villages of Sanandaj province. The 217 fecal samples were collected directly from the rectum of these animals by wearing an apron, hand gloves and gumboot to avoid contamination. Samples were immediately placed in sterile bottles for transport to the laboratory. Samples not tested immediately were held at $4-8 \mathrm{C}$ for no longer than 3 days. The collected faecal samples were examined by Stoll's ova counting techniques for determining the number of cysts or trophozoites per gram of faeces by their characteristic morphological features as described by Soulsby (Ferry et al., 2004). Morphological tests was conducted in the Department of Parasitology, Faculty of Veterinary Medicine, University of Tehran. Fecal samples were collected at day 3, pretreatment, and days 8,12 , post treatment, for cyst counts to show the effect of drug treatment.

\section{Result and discussion}

Of 99 cattle from 217 that were positive for B. sulcata, 30 were selected randomly and placed in two groups, A and B. group A was treated with oxytetracycline and group B was treated with metronidazole. The third group named $\mathrm{C}$ was a positive group and group D was selected as a negative group. Efficacy of drugs used in this study was determined on the basis of reduction in cysts/ trophozoites count of this parasite. The cyst count pre on day 0,3 , 8 and 12 was different in the groups A, B, C and D as given in (Table 6). The comparative efficacy of oxytetracycline and metronidazole on day 12 was $66 \%$ and $32 \%$ respectively (Table7).

Table 6: Buxtonella Sulcata Cyst Count Before and after Treatment

\begin{tabular}{llll}
\hline Name of drug & \multicolumn{4}{l}{ Efficacy of drug at different days } \\
\hline & 3 & 8 & 12 \\
oxytetracycline & 20 & 37 & 66 \\
metronidazole & 7 & 21 & 32 \\
\hline
\end{tabular}

Table 7: Efficacy of Oxytetracycline and Metronidazole at Different Days Name of B.coli cyst count at different days post treatment

\begin{tabular}{lllll} 
groups & 0 & 3 & 8 & 12 \\
\hline $\begin{array}{l}\text { A - Oxytet- } \\
\text { racycline }\end{array}$ & $318.17 \pm 35$. & $273.19 \pm 18$. & $201.45 \pm 29$. & $109.17 \pm 19$. \\
$\begin{array}{l}\text { treated } \\
\text { B - Metroni- }\end{array}$ & 19 & 14 & 73 & 38 \\
$\begin{array}{l}\text { dazole treat- } \\
\text { ed }\end{array}$ & 43 & & & \\
C - positive & $301.01 \pm 11$. & $308.13 \pm 21$. & $309.16 \pm 41$. & $308.18 \pm 25$. \\
$\begin{array}{l}\text { control group } \\
\text { D - negative }\end{array}$ & 21 & $297.16 \pm 13$. & $243.16 \pm 15$. & $210.08 \pm 21$. \\
control group & $0.00 \pm 0.00$ & $0.00 \pm 0.00$ & $0.00 \pm 0.00$ & $0.00 \pm 0.00$ \\
\hline
\end{tabular}

Animals that were treated with oxytetracycline showed a statistically significant reduction in mean faecal cyst count This suggests that oxytetracylcine is a useful therapeutic agent against B. sulcata infection but further studies are required to confirm. This study demonstrates that cattle are highly susceptible to B. sulcata infec- 
tion under a variety of housing and environmental conditions in this region of Iran. This is likely to have economic and welfare implications for farmers and cattle in the region and further studies would be beneficial to assess the impact of improved housing conditions, hygiene and therapeutic agents in the control of $B$. sulcata infection in the region. This study showed that oxytetracycline was more effective than oxytetracycline or metronidazole. This study showed a high rate of sensitive to oxytetracycline among isolates B. sulcata. Therefore, the correct selection of appropriate antibiotics to treat infections caused by B. sulcata and prevention of resistance to antibiotics effective against most strains is important.

\section{References}

[1] Aayiz, n. 2005. diagnostic study for cow infection with buxtonella sulcata in iraq. al-qadissiyha j vet sci, 4, 53-56.

[2] Al-zubaidi, m. t. \& al-mayah, k. s. 2011. prevalence of buxtonella sulcata in neonatal and young calves in al-nasir station and some regions in baghdad (al-shuala snd gazaliya).

[3] Ferry, t., bouhour, d., de monbrison, f., laurent, f., dumouchelchampagne, h., picot, s., piens, m. \& granier, p. 2004. severe peritonitis due to balantidium coli acquired in france. european journal of clinical microbiology and infectious diseases, 23, 393-395.

[4] Huang, k.-c. t. c.-c., yang, c.-h. p. c.-h. \& lai, c.-h. 2012. prevalence of gastrointestinal parasites in yellow cattle between taiwan and its offshore islands. thai $j$ vet med, 42, 219-224.

[5] Tomczuk, k., kurek, 1., stec, a., studzinska, m. \& mochol, j. 2005 incidence and clinical aspects of colon ciliate buxtonella sulcata infection in cattle. bull vet inst pulawy, 49, 29-33. 